\title{
Onset of fast ice flow in Recovery Ice Stream, East Antarctica: a comparison of potential causes
}

\author{
K. LANGLEY, ${ }^{1,2,3}$ K. TINTO, ${ }^{2}$ A. BLOCK, ${ }^{2 *}$ R. BELL, ${ }^{2}$ J. KOHLER, ${ }^{3}$ T. SCAMBOS $^{4}$ \\ ${ }^{1}$ Department of Geosciences, University of Oslo, Oslo, Norway \\ E-mail: kirstyl@geo.uio.no \\ ${ }^{2}$ Lamont-Doherty Earth Observatory, Columbia University, Palisades, NY, USA \\ ${ }^{3}$ Norwegian Polar Institute, Fram Centre, Tromsø, Norway \\ ${ }^{4}$ National Snow and Ice Data Center, University of Colorado at Boulder, Boulder, CO, USA
}

\begin{abstract}
Recovery Ice Stream has multiple branches reaching far into the East Antarctic ice sheet. We use new airborne and ground-based geophysics to give the first comprehensive overview of the upper catchment and, by constraining the physical setting, to advance our understanding of the controlling mechanisms for the onset of fast flow. The $400 \mathrm{~km}$ wide ice stream extends towards the Recovery Subglacial Lakes, a region characterized by a crustal boundary, a change in bed roughness, a bedrock topographic step and four topographic basins (A-D), three of which (A-C) contain subglacial water. All these characteristics are considered potential causal mechanisms that contribute to the onset of fast flow. In Lakes B and C the subglacial water is located in basins with sharp downstream ridges, in contrast to the gently sloping ridge on the downstream margin of Lake $A$. The fastest-flowing branch of the ice stream emanates from Lake A. The presence of multiple causal mechanisms along the four Recovery Lakes allows us to identify basal water as a dominant factor for the onset of fast flow, but only if it is stored in a shallow-sided basin where it can lubricate the flow downstream. Relatively minor topographic barriers appear to inhibit streaming.
\end{abstract}

KEYWORDS: Antarctic glaciology, ice streams, subglacial lakes

\section{INTRODUCTION}

Understanding the mechanisms that initiate fast flow in ice sheets is critical to understanding how ice sheets respond to external forcings. Potential controls have been summarized by Winsborrow and others (2010) and include topographic focusing, topographic steps, macroscale topographic roughness, calving margins, subglacial geology, geothermal heat flux and subglacial meltwater routing. With the exception of the calving margin, each of these controls can play a role in the onset of Recovery Ice Stream, East Antarctica, which occurs over a broad region divided into distinct branches. By comparing the topography, geology and bed conditions across this region, we can compare the relative importance of the control mechanisms in order to better understand the hierarchy of factors that influence ice-stream initiation.

\section{Regional setting}

Recovery Ice Stream drains a large catchment covering $8 \%$ of the East Antarctic ice sheet (Joughin and Bamber, 2005), extending $>800 \mathrm{~km}$ inland (Jezek, 1999) and widening to a broad, $400 \mathrm{~km}$ wide region of fast flow (Fig. 1a) organized into multiple branches.

The inland extent of Recovery Ice Stream reaches towards the Recovery Lakes region, on the western edge of the Recovery Highlands. The Recovery Highlands is a $200 \mathrm{~km}$ wide mountain belt with average subglacial elevations of $900 \mathrm{~m}$; the rugged topography includes peaks reaching $>1600$ ma.s.l. (Fig. 1b). The Recovery Lakes region, in contrast, has an average elevation of 600-1500 m below sea level (b.s.l.). In the entire onset region, the bed topography is generally flat, except for the four deep topographic basins

*Present address: Chevron Energy Technology Company, Houston, TX, USA. that are aligned along the Highlands Lakes boundary, features originally identified as subglacial lakes (Bell and others, 2007; Fig. 1b).

The Recovery Lake basins were first identified from satellite imagery and satellite-derived ice surface elevations (Bell and others, 2007). The three northern lake basins were identified by their relatively flat ice surfaces (Fig. 1c) bounded by $3-15 \mathrm{~m}$ surface troughs on the upstream margin and 2-10 m surface ridges on the downstream side, similar features to the well-studied Vostok Subglacial Lake (Studinger and others, 2003). The Recovery Lake basins are among the largest identified subglacial lake basins in Antarctica (A: $3915 \mathrm{~km}^{2}$; B: $4385 \mathrm{~km}^{2}$; C: $1490 \mathrm{~km}^{2}$; D: $3540 \mathrm{~km}^{2}$ ) and are comparable in size to Lakes $90^{\circ} \mathrm{E}\left(2420 \mathrm{~km}^{2}\right)$ and Sovietskaya $\left(1745 \mathrm{~km}^{2}\right)$.

Recent ice radar soundings, incorporated into the BEDMAP2 compilation (Fretwell and others, 2013) and described in more detail below, showed that these basins are $\sim 30-50 \mathrm{~km}$ wide, with bed depths reaching $\sim 1500 \mathrm{~m}$ b.s.l. (Fig. 1b). The $800-1000 \mathrm{~m}$ topographic step from the Highlands to the lakes represents the well-defined upstream edge of Lakes $\mathrm{C}$ and $\mathrm{D}$ in flowline profiles across the lake basins (Fig. 2). A smaller $500 \mathrm{~m}$ high ridge bounds the upstream edge of both Lakes A and B. The downstream margins of Lakes B, C and D each have similar $500 \mathrm{~m}$ high, $20 \mathrm{~km}$ wide ridges. The downstream margin of Lake $A$ is more gradual, with no well-defined ridge.

Bell and others (2007) suggested that the presence of water in the Recovery Lakes region is directly linked to the mechanism for onset of streaming, through basal lubrication and accretion of a more readily deformed basal ice layer. While faster flow originates at the downstream end of the lake basins (Rignot and others, 2011), the pattern of the velocity increase is not uniform for all the lakes. Velocities 

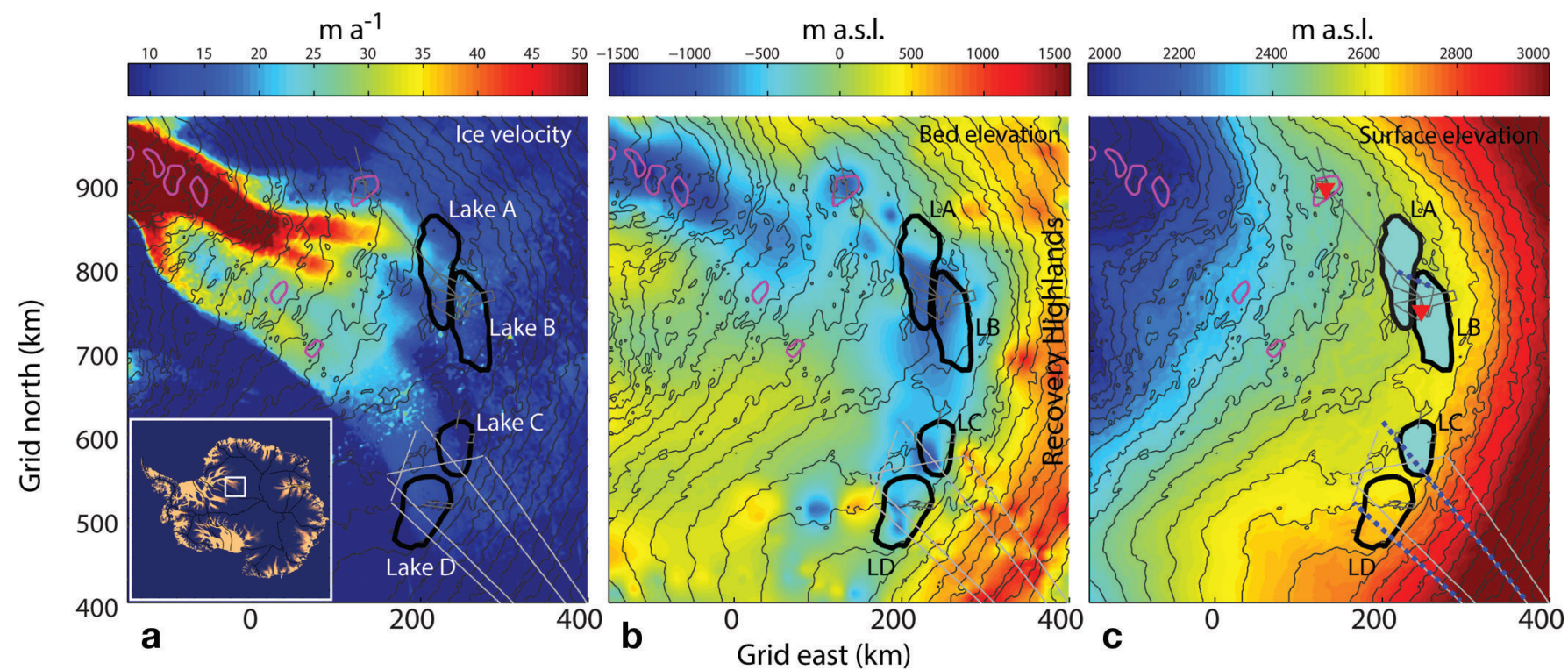

Fig. 1. (a) Ice velocity (Rignot and others, 2011), (b) bed elevation (Fretwell and others, 2013) and (c) surface elevation (Bamber and others, 2009), for the upper Recovery catchment showing the Recovery Lake basins (Bell and others, 2007), labelled Lakes A-D in (a) and abbreviated to LA-LD in (b) and (c) and the other figures. In (c), the marine shaded infill indicates the presence of basal water, as interpreted from ground-based surveys (dark grey line (Langley and others, 2011)) and airborne radar data (light grey line (Block, 2011)). Ground-based continuous GPS locations are marked by red stars. Blue dashed lines indicate the profiles shown in Figure 3. Pink outlines show active lakes determined from the Ice, Cloud and land Elevation Satellite (ICESat) (Smith and others, 2009). Surface contours are shown in light grey (Bamber and others, 2009). Inset: Location of the study area; Antarctic ice velocity (Rignot and others, 2011) and basin catchments (black lines). White box indicates the area covered by $(\mathrm{a}-\mathrm{c})$.

in these regions are still low, but organized flow can be traced from each onset region into the main trunk of Recovery Glacier. To the north, two relatively fast-flowing narrow branches of the ice stream extend close to the lakes (Fig. 1a), with the fastest-flowing branch of the ice stream reaching close to the western margin of Lake $A$, where the ice velocity increases steadily once the ice crosses the margin of the basin (Fig. 2b). Less than $50 \mathrm{~km}$ downstream of Lake A, ice is moving at $30 \mathrm{~m} \mathrm{a}^{-1}$. Along a southern flowline, traversing both Lakes $A$ and $B$, this speed is not attained until $75 \mathrm{~km}$ downstream of the lakes (Fig. 2c).

Farther south, a broad, $100 \mathrm{~km}$ wide onset region reaches towards Lakes $\mathrm{C}$ and D (Fig. 1a). The increase in velocity from $10 \mathrm{~m} \mathrm{a}^{-1}$ to $25 \mathrm{~m} \mathrm{a}^{-1}$ begins $\sim 200 \mathrm{~km}$ down-flow of these lakes, in the region where smaller active lakes have been identified (Smith and others, 2009; Fricker and others, 2014). In contrast to Lake A, $50 \mathrm{~km}$ from Lake C the ice sheet is moving $<20 \mathrm{~m} \mathrm{a}^{-1}$, while at the same distance from the downflow edge of Lake D, it is moving $<15 \mathrm{~m} \mathrm{a}^{-1}$ (Fig. $2 \mathrm{~d}$ and e).

The four upper branches of Recovery Ice Stream flow out from the four Recovery Lake basins, but as described, ice velocity develops at different rates from each of the basins. By examining the nature of the lake basins, from their topography, geology and water content, we identify the combination of factors that are critical to the onset of ice streaming in the Recovery catchment.

\section{METHODS}

Prior to 2009, the morphology of the Recovery lake basins and onset region could only be inferred through very limited measurements of ice thickness and gravity made along a surface traverse route in the 1960s (Clough and others, 1968).

New ground and airborne geophysical data were obtained in early 2009, as part of the International Polar Year
(IPY). Ground-based radar, gravity and GPS were collected by the US-Norway Traverse in 2008/09 (Langley and others, 2011) over all four basins, although mostly A and B. Airborne geophysical data (radar, laser, gravity and magnetics) were collected by the AGAP (Antarctica's Gamburtev Province) program in 2009 (Block, 2011) over the southern two lake basins C and D (Fig. 1). These two datasets are combined to provide the first comprehensive overview of all four lake basins and the onset region.

The ground-based radar data were acquired with a $3 \mathrm{MHz}$ impulse dipole radar (Langley and others, 2011). Ground-based gravity surveys were performed with a pair of LaCoste-Romberg gravimeters. Two automated long-term GPS measurement stations, configured for measuring vertical motion of the firn at $\sim 6 \mathrm{~m}$ depth, were deployed on the central Recovery B basin and on a smaller subglacial lake (Rec11 of Smith and others, 2009; Rec9 in Fricker and others, 2014, Supplementary Material, SM-1, online at http://www.igsoc.org/hyperlink/14j067.pdf) north of the main Recovery basins. The AGAP airborne survey included data from a $150 \mathrm{MHz}$ radar system (Block, 2011; Wolovick and others, 2013) and a Sander Geophysics AIRGrav gravimeter (Studinger and others, 2008).

We use the radar data to evaluate the presence of water by calculating basal hydraulic head, anomalous bed reflectivity and bed roughness along the survey lines (Oswald and Robin, 1973; Siegert and others, 1996; Carter and others, 2007). Hydraulic head is a measure of potential water flow at the bed (Oswald and Robin, 1973); water will drain in the direction of lower hydraulic head and collect in regions with hydraulic minima (Supplementary Material, SM-1, http:// www.igsoc.org/hyperlink/14j067.pdf).

Radar bed-returned power was converted to bed reflectivity following Matsuoka and others (2010), after correcting for system characteristics, a geometric factor 


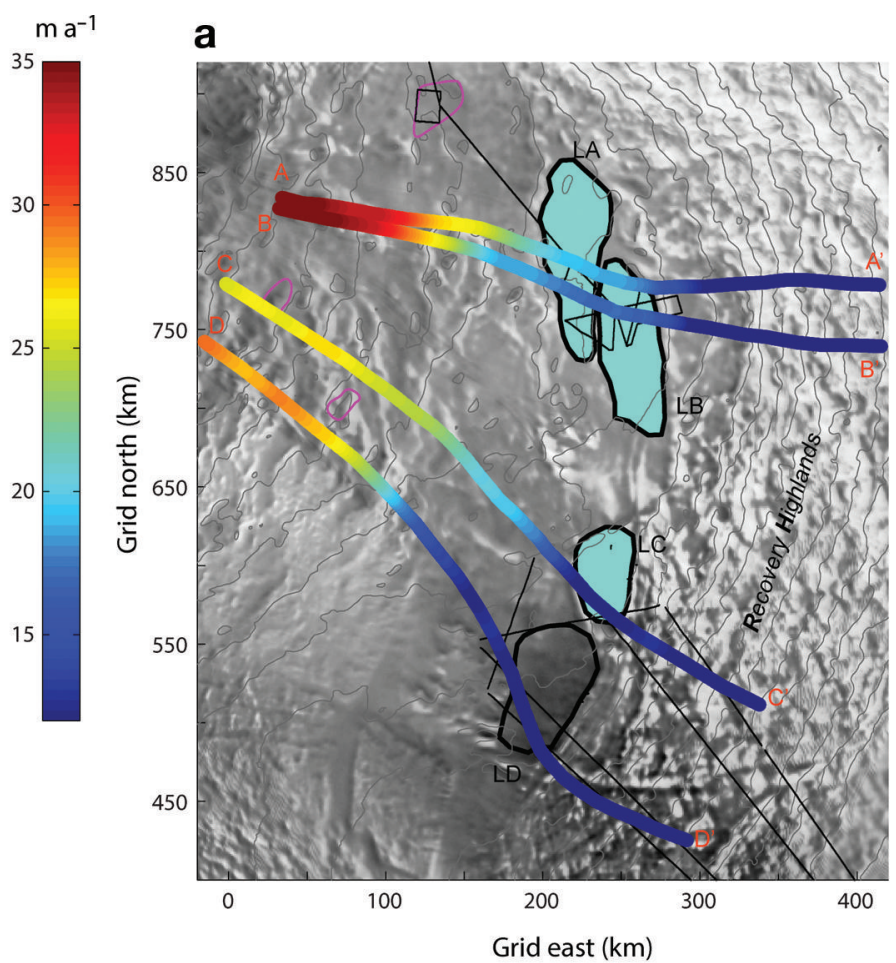

b
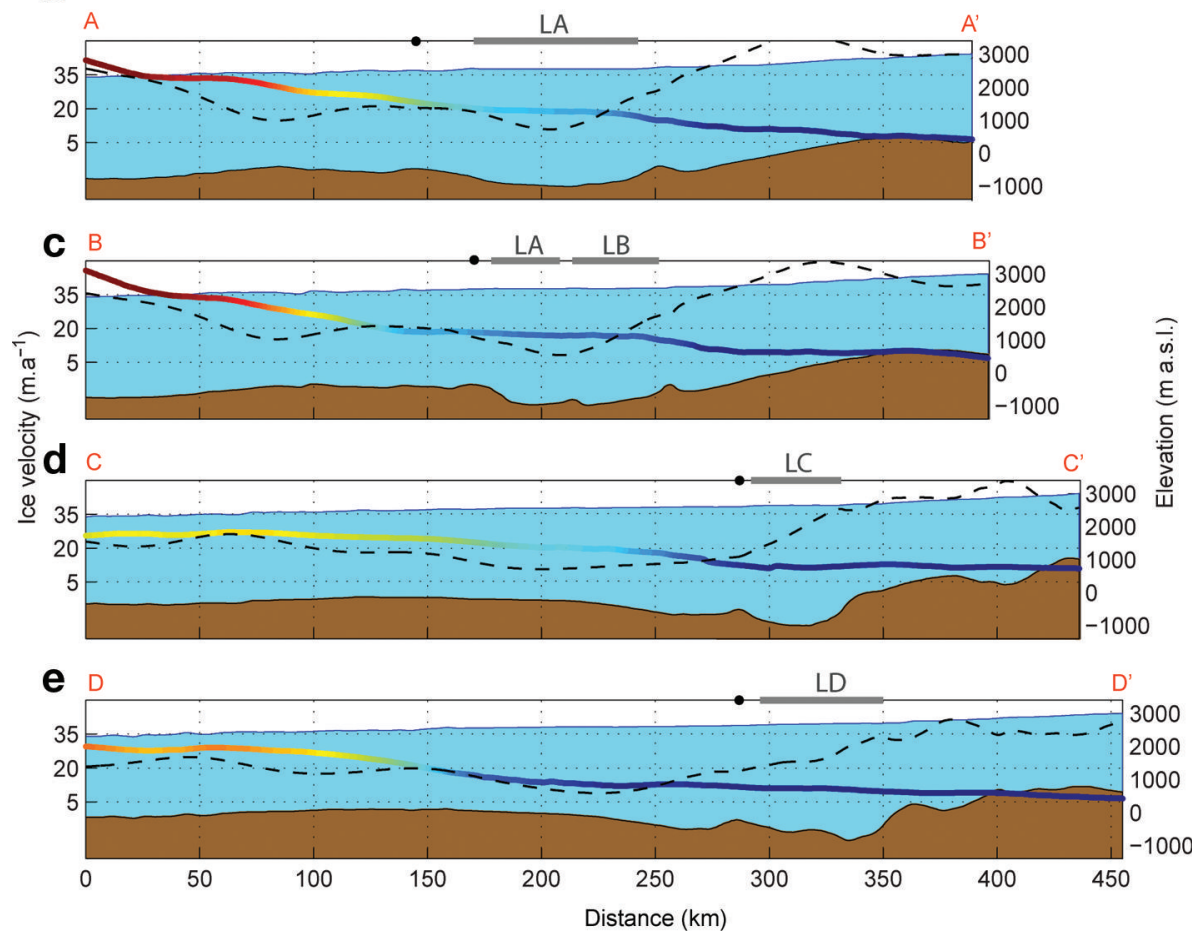

Fig. 2. (a) Upper Recovery catchment showing flowlines derived from ice velocity vectors (Rignot and others, 2011), smoothed over ten ice thicknesses and colour-coded according to flow speed. Recovery Lake basins (Bell and others, 2007) are labelled LA-LD. The marine shaded infill indicates the presence of basal water, as interpreted from ground-based (dark grey line (Langley and others, 2011)) and airborne radar surveys presented here (light grey line). Pink outlines are active lakes determined from ICESat (Smith and others, 2009); surface contours are shown in light grey (Bamber and others, 2009). Background image is RADARSAT (Liu and others, 2001). (b-e) Flowline cross section through each lake basin illustrating how surface elevation (Bamber and others, 2009), bed elevation (Fretwell and others, 2013), driving stress (black dashed line; derived from surface elevations smoothed over 20 ice thicknesses) and velocity (coloured line, from Rignot and others, 2011) develop along flow. The Recovery Lakes are labelled LA-LD and their extent (Bell and others, 2007) indicated by the grey bars. The upstream Recovery Highlands are labelled; the downstream ridges are marked by a black dot.

proportional to ice thickness, and the depth-averaged oneway attenuation rate (details in Supplementary Material, SM-1, http://www.igsoc.org/hyperlink/14j067.pdf). Bed reflectivity is characterized by the brightness residual, the deviation of the measured value from that predicted for a given attenuation rate. Higher values (or brighter regions) are anticipated over clean ice/water interfaces, as opposed to ice/sediment or grounded ice regions (Winebrenner and others, 2003; Jacobel and others, 2009; Langley and others, 2011). 
Bed roughness is determined from bed elevation data following Rippin and others (2011), described here by a dimensionless number (details in Supplementary Material, SM-1, http://www.igsoc.org/hyperlink/14j067.pdf). All else being equal, an extensive ice/water interface will have a low roughness value compared to an ice/sediment or ice/rock interface. Radar measurements of ice thickness and bed topography have an accuracy of $12.5 \mathrm{~m}$ for the ground-based system (Langley and others, 2011) and $40 \mathrm{~m}$ for the airborne system (Block, 2011) based on crossover analysis. The vertical range resolution of the two systems is 28 and $0.56 \mathrm{~m}$ respectively, based on the bandwidth.

The geological setting of the Recovery Lakes was investigated by comparing the observed gravity anomalies with those predicted from two-dimensional models along the survey lines. Forward models of the gravity across the Recovery Lake basins were constructed assuming three bodies: ice, crustal rock, and mantle (details in Supplementary Material, SM-2, http://www.igsoc.org/hyperlink/14j067. pdf). Bed topography at the ice/crustal-rock interface was identified from the radar surveys, and the crust/mantle boundary was modelled using an Airy approximation and crustal thickness of $43.1 \mathrm{~km}$ as determined teleseismically at the AGAP camp (Hansen and others, 2010). Smaller-scale forward models of gravity across the lake basins were used to identify the presence or absence of low-density sediments within the lake basins. The same ice and crustal-rock bodies were used as above, but with the long-wavelength gravity field accounted for by applying a linear correction between the upstream and downstream edges of the basins. This allowed us to compare the shape of the anomaly across each basin with that predicted from the measured bed to isolate areas of low-density sediments within the basins.

Finally, ice velocities as well as vertical motion were measured with the ground-based continuous GPS (cGPS) over a 16 month period (details in Supplementary Material, SM-3, http://www.igsoc.org/hyperlink/14j067.pdf).

\section{RESULTS}

\section{Crustal structure}

Satellite and aeromagnetic data suggest that the Recovery region is a Precambrian basement province, distinct from the adjacent South Pole, Gamburtsev and Ruker terrains (Ferraccioli and others, 2011). Our new modelling of the gravity field reveals a change in crustal thickness between the upslope Recovery Highlands to the east and the Recovery Lakes region (Fig. 2 of Supplementary Material, http://www.igsoc.org/hyperlink/14j067.pdf). We find a good $(\mathrm{rms}=12.6)$ fit between the observed gravity and the forward model of profile 32002 across Lake D (Figs 2 and 3 of Supplementary Material, http://www.igsoc.org/hyperlink/ 14j067.pdf), with Moho topography calculated assuming Airy isostasy, to derive a change in crustal thickness similar to model results based on the 1960s traverse data across the Lakes A and B region (Bell and others, 2007).

The presence of a crustal boundary offers three of the seven potential controls for ice streaming (Winsborrow and others, 2010): a change in geothermal heat flux, a topographic step, and a change in macroscale topographic roughness.

Geothermal heat flux controls the temperature at the base of the ice sheet, influencing the viscosity of the basal ice as well as the location and amount of basal melt that occurs. Changes in crustal thickness are associated with changes in geothermal heat flux (Mareschal and Jaupart, 2013), although without knowledge of the crust's composition we cannot predict the magnitude, nor even the sign of the change. Heterogeneity of shallow geology between the lake basins is suggested by the high Bouguer anomaly over Lake A and the greater magnetic anomaly over Lake C relative to D (Fig. 2 of Supplementary Material, http://www. igsoc.org/hyperlink/14j067.pdf).

All four basins occur near the edge of the crustal boundary, and so will experience the same large-scale changes in geothermal flux associated with this change in crustal thickness. The geological variations inferred between individual lake basins could be associated with further variations in geothermal flux, but the magnitude of these cannot be constrained here. We observe that the difference in geological material underlying Lakes $C$ and $D$ does not result in different ice flow behaviour between the two lakes. We cannot rule out a change in geothermal heat flux associated with the relatively high Bouguer anomaly at Lake A.

\section{Topographic step}

The topographic controls on ice streaming are topographic focusing or a topographic step. Topographic focusing occurs where ice is funnelled through a bedrock trough, leading to increased velocity with the increased flux. The main trunk of Recovery Glacier flows through a deep trough, but the region where the velocity increase is first observed is relatively broad (Fig. 1b). A topographic step can influence ice streaming since there will be an increase in strain heating as ice flows over the step, leading to an increase in velocity downstream. A well-defined 800-1000 m topographic step extending for $\sim 400 \mathrm{~km}$ in a north-south direction separates the elevated Recovery Highlands from the low-lying Recovery Lakes region (Fig. 1b), and is associated with a significant increase in ice thickness, from $\sim 2200 \mathrm{~m}$ over the Recovery Highlands to $>3200 \mathrm{~m}$ in the Recovery Lakes region. This topographic step separates the Recovery Highlands from the four lake basins (Fig. $3 a$ and b), although it is closer to the upstream edges of Lakes $C$ and D than the two northern lakes. A change in the regional ice surface slope also occurs at the topographic step (Fig. 1c). The increase in both ice thickness and ice surface slope results in an increased driving stress as the ice flows off the Recovery Highlands into the lake basins (Fig. 2b-e). The driving stress is reduced over the lake basins due to the level ice surface. The topographic step control therefore applies to all four basins, but its effects are expected to be felt most strongly at Lakes C and D.

\section{Basal roughness}

Basal roughness affects the friction at the glacier bed, with both the wavelength and orientation of bed topography exerting an influence on flow. Airborne radar reveals a change in basal roughness across the crustal boundary as ice moves from the rugged Highland topography to the smooth lake-region topography. Roughness shifts from on average 60 (dimensionless units) over the Recovery Highlands to 2040 over the Recovery Lakes region. This change in roughness is evident across both Lakes C and D, with smooth topography also apparent over Lakes A and B (Fig. 3).

\section{Basin geology}

The change from the very rugged topography of the Highlands to the smooth topography of the lake basins could be indicative of sediment infill in the topographic 

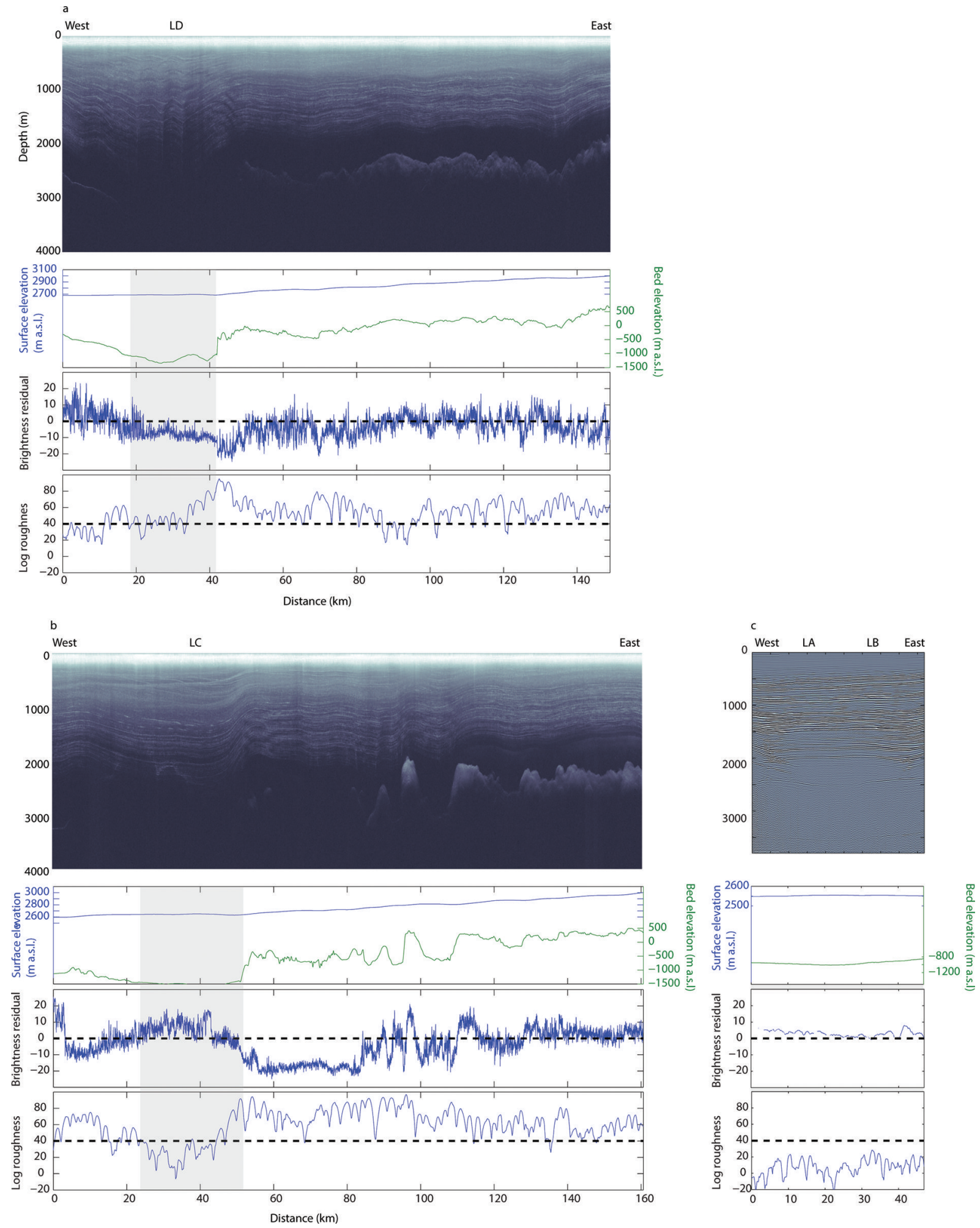

Fig. 3. Radargram, surface and bed elevation, brightness residual and bed roughness derived from the radar data for (a) LD, (b) LC and (c) LA LB. The shaded regions in the lower line plots of each panel indicate the Recovery Lake extents proposed by Bell and others (2007). The profile locations are given by the blue dashed lines in Figure 1c.

lows. As well as this change in roughness, sedimentary basins can provide a source for lubricating sediment downstream of the basin and affect the routing of subglacial water. Lakes A and B lie at similar depths, $\sim 1000 \mathrm{mb}$ b.l. Lake $C$ is the deepest, at $\sim 1100 \mathrm{~m}$, while Lake $\mathrm{D}$ is up to $\sim 900 \mathrm{~m}$ deep. When topography is corrected for removal of the current ice load, Lakes A and B are close to sea level and Lake $\mathrm{C}$ is $\sim 100 \mathrm{~m}$ b.s.l. and could therefore have collected marine sediments in the absence of the ice sheet. Lake D remains $\sim 100 \mathrm{~m}$ a.s.l. when ice load is removed.

Modelling the gravity anomaly over Lakes A, B and D indicates that the subglacial topography alone is sufficient to produce the observed gravity field and does not suggest an increased thickness of low-density sediments within the basins (Supplementary Material, SM-2, http://www.igsoc. org/hyperlink/14j067.pdf). A high Bouguer anomaly in Lake 
C, and even higher in the centre of Lake A, suggests that the centre of the basins may in fact be more dense than their margins (Fig. 1 of Supplementary Material, http://www. igsoc.org/hyperlink/14j067.pdf).

Using the Bouguer slab approximation, modelling of airborne gravity with an accuracy of $0.5 \mathrm{mGal}$ can only resolve relative changes in sediment thickness greater than $25 \mathrm{~m}$, and even the higher-resolution $(0.1 \mathrm{mGal})$ ground-based gravity data may miss a thin layer of sediments. The relatively smooth topography of the Recovery Lake region could therefore be the result of a basin fill of $<25 \mathrm{~m}$ of sediment, or a widespread drape of sediments across the lowlands.

\section{Basal water}

Basal water is an important control on ice-streaming behaviour as it strongly influences the friction at the bed and the potential for basal sliding, and can be highly variable, both in its spatial and temporal distribution. There is clear evidence of a robust subglacial network within Recovery Ice Stream from the observations of active subglacial lakes (Smith and others, 2009; Fricker and others, 2014) co-located with areas of high ice-flow velocities. All four of the large lake basins are hydraulic minima (Fig. 1 of Supplementary Material, http://www.igsoc.org/hyperlink/ 14j067.pdf), although $A$ has a smaller downstream hydraulic boundary $(\sim 20 \mathrm{~m})$ than $C$ and $D(\sim 50 \mathrm{~m})$. Lakes $A$ and $B$ are hydraulically connected at the northern end (Langley and others, 2011), but a hydraulic boundary exists between them along the southern three profiles (Fig. 1 of Supplementary Material, http://www.igsoc.org/hyperlink/14j067.pdf). Analysis of the ground-based radar data over the northern two lakes has been used to map the distribution of subglacial water in these basins (Langley and others, 2011). Locations with high relative radar brightness and low roughness can be interpreted as water or water-rich environments (Oswald and Robin, 1973; Siegert, 2000; Carter and others, 2007; Jacobel and others, 2009).

Lake A has the clearest indication of subglacial water. The southern third of the lake basin has a smooth and anomalously strong reflectivity, indicating a clean interface between the ice sheet and a basal water body. Intermediate values of the basal reflectivity and roughness over Lake B are indicative of a water-rich environment, but the absence of a uniformly flat reflector indicates there is not a clean lake-like interface.

The airborne radar data over Lakes $\mathrm{C}$ and $\mathrm{D}$ provide the first constraints on the distribution of water in these basins. Lake C has a $3.5 \mathrm{~km}$ long smooth bright reflector (Fig. $3 \mathrm{~b}$ ) in the centre of the basin, similar to reflections interpreted as water in Langley and others (2011). This bright reflector is located in a $25 \mathrm{~km}$ wide region where the brightness residual is high $(>0 \mathrm{~dB})$ and roughness is low $(<40)$. This suggests that Lake $C$ has a relatively small $3.5 \mathrm{~km}$ wide water body located in a $25 \mathrm{~km}$ wide water-rich environment. In contrast, no bright flat reflector was imaged over Lake D. The absence of a bright smooth bed over the topographic minimum (Fig. 3a) indicates that the lake basin is likely dry at present.

Detection of basal water in a radar profile is based on a relative comparison of the reflected power and roughness of the basal interface. Even a thin layer of water will modify the amplitude and form of the reflected pulse due to the high dielectric contrast between ice and water. Since we do not see evidence of a clear water bed reflection in our data, we are unable to resolve the thickness of the water layer with the radar, and rely on gravity measurements for evidence of the water layer thickness. The accuracy of the airborne gravimeter gives a detection limit of $\sim 7 \mathrm{~m}$ water column thickness, as the gravity signature of water, rather than rock, at the lake bed will be $\sim 3.5$ times that of low-density sediments. Forward models of the lake basins did not reveal evidence of low-density material in the lake basins, and so provide no evidence for a thick water layer. Thus we infer that while radar surveys identify thin water layers underlying parts of the A, B and C topographic basins, their thickness is on the order of meters, and not hundreds of meters as is the case for Vostok Subglacial Lake.

Data from the two cGPS systems were used to estimate an upper limit on the rate at which the two sites (Recovery B and Rec9) might be experiencing uplift due to filling of the subglacial reservoirs. The results show that nearly all the vertical motion can be attributed to firn compaction at the base of the antenna poles (initially 6.5 and $6.1 \mathrm{~m}$ below the surface, respectively). Downward movement, at the rate of $0-2 \mathrm{~cm} \mathrm{a}^{-1}$, cannot be ruled out. No attempt was made to account for vertical strain in association with the horizontal movement of the stations $\left(11.93 \mathrm{~m} \mathrm{a}^{-1}\right.$, bearing $277^{\circ}$, and $14.12 \mathrm{~m} \mathrm{a}^{-1}$, bearing $246^{\circ}$, respectively), but this is probably negligible over the lake basin surfaces.

Refreezing to the base of the ice sheet can occur as the ice sheet flows over a subglacial lake, as for example at Lakes Vostok and Concordia (Jouzel and others, 1999; Bell and others, 2002; Tikku and others, 2005). Bell and others (2007) suggested that accreted ice could facilitate the onset of fast flow in the Recovery region, through the addition of a relatively warm, and thus more readily deformable, layer of basal ice. In the Gamburtsev Mountains (Bell and others, 2011), refrozen ice and internal layers were imaged at depths greater than $2.5 \mathrm{~km}$ as part of the same airborne campaign presented here. Both the airborne and surface radar systems were able to resolve ice thickness in the Recovery region to depths as great as $\sim 3.5 \mathrm{~km}$. However, bed returns were generally very weak (Fig. 3), and few internal layers or other structures were imaged below $2.5 \mathrm{~km}$, perhaps indicative of warmer ice and higher attenuation. Thus, it remains ambiguous whether refrozen ice is present in the Recovery Lakes region.

\section{DISCUSSION}

The $400 \mathrm{~km}$ wide Recovery Lakes region contains many of the mechanisms considered to be potential controls for the onset of fast flow, including a crustal boundary that can support a change in geothermal heat flux, a change in roughness, a topographic step and topographic basins. The presence of water or water-rich environments in three of the basins (A-C), and a dry lake basin (D) allows us to examine the relative roles of water and other factors on the onset of fast flow.

Only Lake A is directly located at the onset of fast flow. Water may be the critical factor for triggering the onset at the downstream edge of Lake A, since it seems to be the most unambiguously lake-like. While all four lakes sit near a crustal boundary and experience a likely change in geothermal heat flux, the local Bouguer anomaly at Lake A (Fig. 2 of Supplementary Material, http://www.igsoc.org/ hyperlink/14j067.pdf) is twice as large as other local variations, and may be associated with further variations in geothermal heat flux, which could continue beyond the 
lake boundary along the surveyed line. Increased water production in the vicinity of Lake A would explain the observed higher water content of the Lake A basin, but this is not well constrained.

Lake D has a topographic step, a change in geothermal flux, a change in roughness and possible topographic forcing, but there is no change in velocity for $>150 \mathrm{~km}$ downstream. The absence of water in Lake D is a likely candidate to explain why fast flow does not occur at the downstream edge of this dry lake basin.

Lakes C and B both have water or water-rich environments, a step change in roughness, and a likely change in geothermal flux, yet are not directly associated with streaming onset. While Lake A might experience greater water production in the presence of a potential increase in geothermal heat, lakes A, B and C all show clear signs of the presence of water. The only significant difference, beyond this, between Lakes $\mathrm{A}$ and $\mathrm{B} / \mathrm{C}$ is the topography at the downstream edge of the lakes. Lake $A$ has a gently sloping margin, in contrast to the steeper edges of B and C. While the limited coverage of ice thickness data from the region prevents a detailed analysis of hydrologic pathways, along our survey lines we see that the downstream margin of Lake A presents a lower hydraulic barrier than the margins at either Lake C or B (along the southern three profiles). We suggest that the bounding topographic ridges of $\mathrm{C}$ and $\mathrm{B}$ prevent water from moving out of these subglacial lakes. This is significant since we observe that the fastest ice flow occurs in the areas with active basal drainage systems, as indicated by the presence of the active lakes (e.g. Smith and others, 2009) (Fig. 1).

The cGPS measurements show that, over the 16 month observation period, there was very little surface elevation movement on either of the surveyed lakes (Lake B and the smaller lake to the north; Fig. 1) that might indicate filling or draining (Fig. 5 of Supplementary Material, http://www. igsoc.org/hyperlink/14j067.pdf). Alternatively, the observations can be explained by a constant flux of water moving through these systems. Since Lake B is hydraulically connected to Lake $A$ at the northern end (Langley and others, 2011; Fig. 1 of Supplementary Material, http://www. igsoc.org/hyperlink/14j067.pdf) we would expect surface variations linked to basal water to be consistent between these two. The total amount of water in the system cannot be determined here; however, we believe the critical factor is the presence of water and its ability to overcome hydrological barriers to move through the system.

Water in subglacial lakes can be important in initiating fast flow, but if the lake is steep-sided on the downstream edge, water is effectively prevented from flowing along this path, suppressing the onset of fast flow. This is supported by the difference in fast-flow onset from the Recovery Lakes and also from the steep-sided tectonically controlled lakes (e.g. Vostok Subglacial Lake or $90^{\circ}$ E Lake) that do not appear to foster the onset of fast flow. Though refreezing of water to the base of the ice sheet may influence the ice flow out of the Recovery Lakes, the inability of the radar systems to image the deeper internal structures leaves the role of refrozen lake water unresolved. The onset of fast flow at the downstream margin of Lake A is evidence that water stored in broader basins with gentle bounding topography is more likely to be connected to the downstream subglacial hydrologic network and more likely to foster the onset of fast flow.

\section{CONCLUSIONS}

Recovery Ice Stream extends far inland, terminating along its northernmost edge in the Recovery Lakes. New geophysical data allow us to describe the physical setting of this upper catchment area, which fosters the onset of Recovery Ice Stream. The region is characterized by a crustal boundary, a change in bed roughness, a topographic step and four topographic basins (A-D). A crustal boundary separates the elevated Recovery Highlands, underlain by thicker crust to the east, and the low-lying smooth Recovery Lakes region, underlain by thinner crust to the west. This crustal boundary controls both a 500-1000 m high topographic step and a regional change in roughness. Three of the topographic basins in the Recovery Lakes region contain water (Lakes AC). In Lakes B and C the subglacial water is located in basins with sharp downstream ridges, in contrast to the gradual slopes on the downstream margin of Lake A. The fastestflowing branch of the ice stream reaches the margin of Lake A, the only lake basin with a shallow slope that may allow the water to escape. The presence of multiple potential control mechanisms along the four Recovery Lakes region allows us to establish that basal water is a dominant factor for the onset of fast flow but only if it is stored in a shallowsided basin where it can lubricate the flow downstream. Relatively minor topographic barriers appear to inhibit the onset of streaming out of Lakes B and C. Other proposed controls (e.g. topographic steps, changes in bed roughness, changes in geothermal flux, and lubricating sediments) appear to have a lesser influence.

\section{ACKNOWLEDGEMENTS}

We acknowledge all members of the Norwegian-US IPY traverse and the AGAP field teams. The ground-based work was carried out under the umbrella of the International Trans-Antarctic Scientific Expedition (ITASE)-Ice Divide of East Antarctica (IDEA) within the framework of IPY project No. 152 funded by the Norwegian Polar Institute (NPI), the Research Council of Norway and the US National Science Foundation (NSF). This work is also a contribution to ITASE. K. Langley was supported in part by the Center for Ice, Climate and Ecosystems (ICE) of the NPI. We acknowledge the seven nations involved in the AGAP IPY effort for their logistical, financial and intellectual support. Specifically the US Antarctic Program of the NSF provided support for the logistics, development of the instrumentation and analysis of the data. The UK Natural Environment Research Council (NERC)/British Antarctic Survey (BAS) provided extensive support for deep-field logistics, data collection and analysis. The Federal Institute for Geosciences and Resources, Germany (BGR), and the Polar Research Institute of China provided invaluable support to the program. K. Langley's visit was supported by the Lamont-Doherty Marie Tharp Fellowship.

\section{REFERENCES}

Bamber JL, Gomez-Dans JL and Griggs JA (2009) A new $1 \mathrm{~km}$ digital elevation model of the Antarctic derived from combined satellite radar and laser data - Part 1: data and methods. Cryosphere, 3(1), 101-111 (doi: 10.5194/tc-3-101-2009)

Bell RE, Studinger M, Tikku AA, Clarke GKC, Gutner MM and Meertens C (2002) Origin and fate of Lake Vostok water frozen 
to the base of the East Antarctic ice sheet. Nature, 416(6878), 307-310 (doi: 10.1038/416307a)

Bell RE, Studinger M, Shuman CA, Fahnestock MA and Joughin I (2007) Large subglacial lakes in East Antarctica at the onset of fast-flowing ice streams. Nature, 445(7130), 904-907 (doi: 10.1038 /nature05554)

Bell RE and 11 others (2011) Widespread persistent thickening of the East Antarctic Ice Sheet by freezing from the base. Science, 331(6024), 1592-1595 (doi: 10.1126/science.1200109)

Block AE (2011) Geophysical perspectives of subglacial settings and their influence on glacial dynamics. (PhD thesis, Columbia University)

Carter SP, Blankenship DD, Peters MF, Young DA, Holt JW and Morse DL (2007) Radar-based subglacial lake classification in Antarctica. Geochem. Geophys. Geosyst., 8(3), Q03016 (doi: 10.1029/2006GC001408)

Clough JW, Bentley CR and Poster CK (1968) Ice-thickness investigations on SPQMLT III. Antarct. J. US, 3(4), 96-97

Ferraccioli F, Finn CA, Jordan TA, Bell RE, Anderson LM and Damaske D (2011) East Antarctic rifting triggers uplift of the Gamburtsev Mountains. Nature, 479(7373), 388-392 (doi: 10.1038/nature10566)

Fretwell P and 59 others (2013) Bedmap2: improved ice bed, surface and thickness datasets for Antarctica. Cryosphere, 7(1), 375-393 (doi: 10.5194/tc-7-375-2013)

Fricker H, Carter S, Bell R and Scambos T (2014) Active lakes of Recovery Glacier, East Antarctica: a bedrock-controlled subglacial hydrological system. J. Glaciol., 60(223), 1015-1030 (doi: 10.3189/2014JoG14J063)

Hansen SE, Nyblade AA, Heeszel DS, Wiens DA, Shore P and Kanao M (2010) Crustal structure of the Gamburtsev Mountains, East Antarctica, from S-wave receiver functions and Rayleigh wave phase velocities. Earth Planet. Sci. Lett., 300(3-4), 395-401 (doi: 10.1016/j.epsl.2010.10.022)

Jacobel RW, Welch BC, Osterhouse D, Pettersson R and MacGregor JA (2009) Spatial variation of radar-derived basal conditions on Kamb Ice Stream, West Antarctica. Ann. Glaciol., 50(51), 10-16 (doi: 10.3189/172756409789097504)

Jezek KC (1999) Glaciological properties of the Antarctic ice sheet from RADARSAT-1 synthetic aperture radar imagery. Ann. Glaciol., 29, 286-290 (doi: 10.3189/172756499781820969)

Joughin I and Bamber JL (2005) Thickening of the ice stream catchments feeding the Filchner-Ronne Ice Shelf, Antarctica. Geophys. Res. Lett., 32(17), L17503 (doi: 10.1029/ 2005GL023844)

Jouzel J and 9 others (1999) More than $200 \mathrm{~m}$ of lake ice above subglacial Lake Vostok, Antarctica. Science, 286(5447), 2138-2141 (doi: 10.1126/science.286.5447.2138)

Langley K and 8 others (2011) Recovery Lakes, East Antarctica: radar assessment of sub-glacial water extent. Geophys. Res. Lett., 38(5), L05501 (doi: 10.1029/2010GL046094)
Liu H, Jezek K, Li B and Zhao Z (2001) Radarsat Antarctic Mapping Project digital elevation model Version 2. National Snow and Ice Data Center, Boulder, CO. Digital media: http://nsidc.org/data/ nsidc-0082.html

Mareschal J-C and Jaupart C (2013) Radiogenic heat production, thermal regime and evolution of continental crust. Tectonophysics, 609, 524-534 (doi: 10.1016/j.tecto.2012.12.001)

Matsuoka K, Morse D and Raymond CF (2010) Estimating englacial radar attenuation using depth profiles of the returned power, central West Antarctica. J. Geophys. Res., 115(F2), F02012 (doi: 10.1029/2009JF001496)

Oswald GKA and Robin GdeQ (1973) Lakes beneath the Antarctic ice sheet. Nature, 245(5423), 251-254 (doi: 10.1038/ 245251a0)

Rignot E, Mouginot J and Scheuchl B (2011) Ice flow of the Antarctic Ice Sheet. Science, 333(6048), 1427-1430 (doi: 10.1126/science.1208336)

Rippin D, Vaughan DG and Corr HFJ (2011) The basal roughness of Pine Island Glacier, West Antarctica. J. Glaciol., 57(201), 67-76 (doi: 10.3189/002214311795306574)

Siegert MJ (2000) Antarctic subglacial lakes. Earth-Sci. Rev., 50(1-2), 29-50 (doi: 10.1016/S0012-8252(99)00068-9)

Siegert MJ, Dowdeswell JA, Gorman MR and Mclntyre NF (1996) An inventory of Antarctic sub-glacial lakes. Antarct. Sci., 8(3), 281-286 (doi: 10.1017/S0954102096000405)

Smith BE, Fricker HA, Joughin IR and Tulaczyk S (2009) An inventory of active subglacial lakes in Antarctica detected by ICESat (2003-2008). J. Glaciol., 55(192), 573-595 (doi: 10.3189/002214309789470879)

Studinger M and 11 others (2003) Ice cover, landscape setting, and geological framework of Lake Vostok, East Antarctica. Earth Planet. Sci. Lett., 205(3-4), 195-210 (doi: 10.1016/S0012-821X (02)01041-5)

Studinger M, Bell R and Frearson N (2008) Comparison of AIRGrav and GT-1A airborne gravimeters for research applications. Geophysics, 73(6), 151-161 (doi: 10.1190/1.2969664)

Tikku AA, Bell RE, Studinger M, Clarke GKC, Tabacco I and Ferraccioli $F$ (2005) Influx of meltwater to subglacial Lake Concordia, East Antarctica. J. Glaciol., 51(172), 96-104 (doi: 10.3189/172756505781829494)

Winebrenner DP, Smith BE, Catania GA, Conway HB and Raymond CF (2003) Radio-frequency attenuation beneath Siple Dome, West Antarctica, from wide-angle and profiling radar observations. Ann. Glaciol., 37, 226-232 (doi: 10.3189/ 172756403781815483)

Winsborrow MCM, Clark CD and Stokes CR (2010) What controls the location of ice streams? Earth-Sci. Rev., 103(1-2), 45-59 (doi: 10.1016/j.earscirev.2010.07.003)

Wolovick MJ, Bell RE, Creyts TT and Frearson N (2013) Identification and control of subglacial water networks under Dome A, Antarctica. J. Geophys. Res., 118(1), 140-154 (doi: 10.1029/2012JF002555) 